\title{
Het gouden ei in het literatuuronderwijs: van docentopvattingen naar nieuwe perspectieven op een schoolklassieker
}

\author{
Jeroen Dera
}

\begin{abstract}
Het gouden ei (1984) van Tim Krabbé prijkt op de leeslijst van menig scholier. In dit artikel gaat neerlandicus Jeroen Dera in op de positie van deze novelle in het onderwijs. Aan de hand van een enquête onder havo-en vwo-docenten laat hij zien dat Het gouden ei, en literatuur in bredere zin, op school vooral structuralistisch wordt benaderd. Dera betoogt dat de novelle meer te bieden heeft dan deze traditionele formele benadering, door leerlingen te betrekken bij verschillende literair-analytische concepten die ook meespelen in actuele discussies over bijvoorbeeld machtsverhoudingen, seksisme en racisme. Door Het gouden ei het perspectief van metafictie of ideologie te verstrekken, pleit Dera voor een verrijking van het literatuuronderwijs, weg van de heersende nadruk op formele aspecten.
\end{abstract}

\section{Goud of pyriet: de fascinerende positie van Het gouden ei}

Tim Krabbés succesnovelle Het gouden ei was nog maar net verschenen, of criticus Arie van Dalen noemde het boek in De waarheid 'geen literair product dat de tand des tijds zal doorstaan'. (Van Dalen 1984) Zelden kreeg een recensent minder gelijk. Al vanaf medio jaren tachtig is Het gouden ei niet weg te denken uit de ranglijst van meest gelezen titels op de middelbare school - ook in de meest recente inventarisatie stond het boek weer bovenaan. (Dera 2019: 15) Het tankstation waar Saskia Ehlvest ontvoerd wordt door Raymond Lemorne is inmiddels zo roemrucht, dat het Algemeen Dagblad in zomertijd een artikel wijdde aan die mythische plaats langs de Franse snelweg. (Van Mersbergen 2018) Ook de herdrukken spreken boekdelen: in september 2019 verscheen alweer de $57^{\mathrm{e}}$ druk van de novelle, en het einde is nog niet in zicht.

Toch is Het gouden ei geen klassieker zoals die andere boeken die middelbare scholieren keer op keer op hun leeslijst zetten. De aanslag (1982) van Harry Mulisch, De donkere kamer van Damokles (1958) van Willem Frederik Hermans en Oeroeg (1949) van Hella S. Haasse hebben op menig universitaire leeslijst geprijkt, maar Het gouden ei kan op beduidend minder symbolisch kapitaal rekenen. De ontvangst van het boek was van meet af aan gemengd. Er verscheen weliswaar een juichende recensie in NRC Handelsblad (Vervoort 1984), maar andere recensenten reageerden lauw of afwijzend (bijvoorbeeld Schouten 1984; Warren 1984). Erkenning van de Stichting Fonds voor de Letteren bleef in 1986 ook uit: Krabbé werd resoluut een beurs geweigerd, omdat Het gouden ei te weinig literair gewicht in de schaal zou hebben gelegd.

De eerste en enige onderscheiding die Krabbé voor de novelle kreeg, hing samen met het grote succes dat zijn boek onder havisten en vwo'ers had. In 1993 werd hem de Diepzeeprijs uitgereikt, de prijs die het onderwijstijdschrift Diepzee verleende aan auteurs die middelbare scholieren met hun teksten wisten te vervoeren. Toen de juryvoorzitter van De Gouden Strop een jaar later naar Krabbés populariteit onder leerlingen verwees, beet thrillerschrijver Thomas Ross toe: 'Dubieuzer compliment is haast niet mogelijk.' (Ross 1995) De mening van leerlingen bleek voor hem inferieur aan die van ingewijden.

Naarmate Het gouden ei zich comfortabeler nestelde in de schoolcanon, verschenen er echter steeds meer stukken die een lans braken voor Krabbés literaire verdiensten. 'Er zijn in de jaren ' 80 en '90 van de voorbije eeuw weinig Nederlandstalige romans verschenen die het collectieve geheugen van ons taalgebied op een dusdanige manier hebben doordrongen', 
meende bijvoorbeeld Max Temmerman. (Temmerman 2002) Arjen Fortuin wijdde een uitvoerig stuk aan Krabbé in NRC Handelsblad, waarin hij zich verzette tegen de neiging van collega's om boeken zoals Het gouden ei te framen als thrillers zonder literaire waarde. Voor Fortuin ging het uitdrukkelijk om 'what-if literatuur'. (Fortuin 2009, eigen cursivering) In dit tijdschrift schreef Jeroen Kapteijns een pleidooi om Krabbés thematiek serieuzer te bestuderen, want het betreft hier 'een schrijver met belangwekkende ideeën.' (Kapteijns 1999)

Het gouden ei is kortom een novelle met uitgesproken voor- en tegenstanders, die intussen al tientallen jaren scholieren weet bezig te houden - of dat nu is via een nauwgezette lectuur of via een uittreksel op scholieren.com. Juist over de omgang met Het gouden ei op middelbare scholen, waar het boek zo'n centrale plaats heeft weten te veroveren, is weinig bekend. Dit artikel beoogt dat te veranderen. Daartoe zal eerst verslag worden gedaan van een enquête onder docenten Nederlands, werkzaam op de niveaus havo en vwo, die zicht wil krijgen op de manier waarop docenten Het gouden ei beoordelen en hoe zij het boek inzetten in hun onderwijs. Op basis van de resultaten van die enquête zal vervolgens een voorstel worden gedaan voor twee nieuwe benaderingen van Het gouden ei: een metafictioneel georiënteerde lectuur en een representatiekritische lectuur.

\section{'Een mooi middel voor verhaalanalyse' : havo- en vwo-docenten over Het gouden ei}

Om een indruk te krijgen van de manier waarop docenten Nederlands Het gouden ei evalueren en hoe zij de tekst inzetten in het onderwijs, is een korte enquête over de novelle uitgezet via de zeer actieve Facebookgroep 'Leraar Nederlands'. De enquête, die gedurende drie dagen openstond, leverde responsies op van 164 docenten en was specifiek gericht op leraren die actief zijn in het havo- en vwo-onderwijs. Vmbo-docenten blijven uit beeld, omdat literatuur geen onderdeel uitmaakt van het vmbo-examenprogramma, waardoor hier een ander type argumentatie kan worden verwacht. (vgl. Vervoort 2018)

Allereerst werd de docenten gevraagd of zij gebruikmaakten van Het gouden ei in hun literatuuronderwijs. Daaruit bleek dat ruim een kwart van de docenten $(27,6 \%)$ de novelle inzet in de onderbouw havo/vwo $(n=123)$, terwijl het boek gebruikt wordt door $21,9 \%$ van de bovenbouwdocenten vwo ( $\mathrm{n}=137)$ en liefst $43,8 \%$ van de bovenbouwdocenten havo $(\mathrm{n}=137)$. Hoewel er meer leraren zijn die Het gouden ei niet structureel inzetten in hun onderwijs, zijn er - zeker in het havo-onderwijs - relatief veel docenten die de tekst (nog altijd) in hun lespraktijk verwerken.

Als we ons concentreren op de bovenbouw, dan blijkt dat docenten Het gouden ei gemiddeld vooral als een geschikt boek voor vierdeklassers zien, en dan in het bijzonder voor leerlingen in havo 4 (zie tabel 1).

\begin{tabular}{|c|c|c|c|c|c|c|}
\hline Mate waarin & docenten Het gouden & aanrac & leerl & ingen uit ve & rschillende leer & aren \\
\hline & Percent: & respo & r ant & voordoptie & & \\
\hline $\begin{array}{l}\text { Leerjaar } \\
\text { waarschiinliik }\end{array}$ & Zeer onwaarschijnlijk & Onwa & alijk & Neutraal & Waarschijnlijk & Zeer \\
\hline $\mathrm{H} 4$ & 10.4 & 16.5 & 18.9 & 39.6 & 14.6 & \\
\hline H5 & 22.6 & 29.3 & 17.1 & 22.6 & 8.5 & \\
\hline V4 & 17.1 & 25.0 & 15.9 & 31.7 & 10.4 & \\
\hline V5 & 34.8 & 34.8 & 16.5 & 10.4 & 3.7 & \\
\hline V6 & 60.1 & 23.3 & 8.6 & 4.3 & 3.7 & \\
\hline
\end{tabular}

Tabel 1: Waarschijnlijkheid dat docenten Het gouden ei aanraden aan leerlingen uit verschillende leerjaren, uitgedrukt in percentage responsies per antwoordmogelijkheid op de vraag 'Hoe waarschijnlijk is het dat $\mathrm{u}$ Het gouden ei zou aanraden aan een leerling uit leerjaar $x$ ?' $(\mathrm{n}=164)$ 
De gegevens in de tabel suggereren dat docenten Het gouden ei vooral zien als een boek voor startende literatuurlezers. Leerlingen in het examenjaar - zeker die op het vwo - hebben een veel kleinere kans dat hun docent hen Het gouden ei zou aanraden. ${ }^{1}$ Mogelijk hangt dit samen met de classificatie van het boek op de veelgebruikte website 'Lezen voor de lijst'. Het gouden $e i$ wordt daar ingeschaald op niveau 3, het streefniveau voor havoleerlingen, maar doorgaans te laag voor leerlingen in de hoogste klassen van het vwo. (Witte 2008)

160 van de 164 geënquêteerde docenten hadden Krabbés novelle daadwerkelijk gelezen. Zij beoordeelden de literaire waarde van Het gouden ei gemiddeld met een 6,4 $(S D=1,46)$. Het boek wordt dus als voldoende literair beoordeeld, maar niet als uitgesproken literair - een gegeven dat wordt onderstreept door de modus (7) en door het relatief lage aantal respondenten dat uitgesproken hoog of laag oordeelt (13 docenten beoordeelden de literaire waarde met een 4 of lager; 6 docenten gaven een 9 of een 10).

125 docenten legden in een open vraag uit waarom zij Het gouden ei wel of niet een geslaagde literaire tekst vonden. Ze noemden daarbij 192 argumenten. Opvallend is hoe veel docenten de literaire kwaliteit van Het gouden ei koppelen aan de mate waarin Krabbé literaire procedés inzet, zoals symboliek, motieven, perspectiefwisselingen en tijdsprongen. Bijna de helft van de docenten $(48,8 \%)$ wijst in positieve of negatieve zin op dit soort literaire technieken, samen goed voor $31,8 \%$ van alle argumentaties. Veelgenoemd zijn ook de spanning in het boek (13,0\% van de argumentaties), de geschikte kennismaking met literatuur die Het gouden ei vormt $(12,0 \%)$ en de structuur van de novelle $(10,9 \%)$.

De genoemde argumentaties vertegenwoordigen samen ruim tweederde van alle docentreflecties op de literaire kwaliteit van Het gouden ei. Bij de bepaling van die kwaliteit lijkt de nadruk te liggen op formele aspecten: literaire procedés, spanningsopbouw, structuur. Veel minder vaak worden er argumenten gebruikt met betrekking tot het wereldbeeld dat de novelle oproept of de ideologie die uit Krabbés tekst spreekt. Het criterium dat een literaire tekst aanzet tot denken, bijvoorbeeld over normen en waarden, komt bijvoorbeeld slechts 8 keer voor $(4,2 \%)$.

In die zin lijkt onder docenten een structuralistische benadering van het begrip 'literatuur' te overheersen. Dat bevestigt de indruk die in betogen over de praktijk van het Nederlandse literatuuronderwijs al eerder naar voren is gebracht. (zie bijvoorbeeld Van den Boogaard 2018; Dera 2018; Dera 2020) Die structuralistische oriëntatie van het onderwijs komt daarnaast tot uitdrukking in de antwoorden op de laatste vraag uit de enquête: 'Stelt u wel eens vragen over Het gouden ei op een literatuurmondeling en zo ja, kunt u daar enkele voorbeelden van geven?' 123 docenten gaven aan dat ze zulke vragen stelden (75,0\%). Tezamen gaven zij 267 vragen door, waarvan er liefst $83(31,1 \%)$ gingen over de toepassing van literaire begrippen op Krabbés tekst. Populair blijken vooral de betekenis van Saskia's droom over het gouden ei, de symboliek van het getal 8 , het sleutelmotief, de verhouding tussen fabel en sujet en de functie van de perspectiefwisselingen. Een andere belangrijke focus van de examinatoren zijn de personages, en dan in het bijzonder hun motieven (22,1\% van de vragen) en onderlinge relaties $(10,9 \%)$.

Veel van dit soort vragen zouden leerlingen kunnen voorbereiden aan de hand van J.A. Dautzenbergs bijdrage over Het gouden ei in het Lexicon van literaire werken. (Dautzenberg 1995) Daarin behandelt hij immers het sleutelmotief, de titelverklaring en de getallensymboliek. Ook slaat hij de brug tussen literaire begrippen en personages door de namen van de hoofdpersonen als speaking names te interpreteren en bespreekt hij de psychologische verschillen en overeenkomsten tussen Rex en Lemorne. Dautzenberg - met

\footnotetext{
${ }^{1}$ Dit blijkt ook uit het gegeven dat startende leraren Nederlands Het gouden ei weinig noemen als leestip voor leerlingen in 5 vwo. (vgl. Dera \& Lommerde 2020)
} 
talloze besprekingen op scholieren.com in zijn voetspoor - laat echter ook de nodige kwesties liggen. Interessant is dat uitgerekend die kwesties ook weinig terugkomen in de mondelingvragen van docenten. Zo is er slechts één vraag $(0,4 \%)$ die betrekking heeft op de relatie tussen fictie en werkelijkheid in Het gouden ei en is er eveneens maar één vraag over de normen en waarden van de personages.

In de hedendaagse literatuurwetenschap nemen juist die invalshoeken een belangrijke plaats in. Het loont dan ook de moeite om Het gouden ei te benaderen vanuit het perspectief van metafictie en normen en waarden, omdat de enquête uitwijst dat daar mogelijkheden liggen om de didactiek rond Het gouden ei te voeden - juist ook voor leerlingen die de novelle in mindere mate nodig hebben als een 'kennismaking' met literatuur. Hierna zal ik dan ook twee nieuwe lecturen van Het gouden ei presenteren, steeds gekoppeld aan een dominant perspectief dat docenten nu al in hun onderwijs gebruiken. Eerst geef ik een metafictioneel georiënteerde lezing van de novelle, waarin ik tevens de motieven in Het gouden ei een centrale plaats geef. Daarna analyseer ik de relaties tussen de personages, maar dan door een ideologische bril.

\section{De melkweg en de tennisbal: twee motieven in relatie tot metafictie}

Het gouden ei bevat twee motieven die door Dautzenberg niet worden benoemd en die ook niet terugkeren in de resultaten van de lerarenenquête: een ruimtevaartmotief en een spelmotief. Deze motieven hangen onderling samen en houden allebei verband met een metafictionele laag in de novelle. Concreter: ze maken duidelijk dat de geschiedenis in Het gouden ei fictioneel is door de grens tussen fictie en werkelijkheid onder spanning te zetten.

Het ruimtevaartmotief wordt al geïntroduceerd in de openingszin: 'Gelijkmatig als ruimteschepen bewogen de cabines vol toeristen zich over de lange brede weg naar het zuiden.' (Krabbé 1994: 7) ${ }^{2}$ In zijn recensie van de novelle stelt Jo Braet dat de metaforiek hier de bocht uit vliegt (Braet 1984), maar feitelijk is ze zeer functioneel in relatie tot Saskia's gevreesde nachtmerrie, waarin zij opgesloten in een gouden ei door het heelal vliegt, in de hoop dat ze ooit een tweede ei zal raken en er vrijheid volgt in de vernietiging. (13) De beschrijving van auto's als 'cabines' impliceert eenzelfde soort afgeslotenheid, terwijl de vergelijking met gelijkmatig voortbewegende ruimteschepen suggereert dat de voertuigen elkaar in het heelal niet zullen raken. De openingszin kan kortom moeiteloos betrokken worden op de ruimtevaartmetaforiek uit de droom over het gouden ei, waardoor de novelle van meet af het spanningsveld tussen droom en (verhaal)werkelijkheid opwerpt.

Dat spanningsveld werkt ook door in de slotzin: 'Van geen van beiden werd ooit nog iets vernomen - ze leken van de aardbodem verdwenen'. (86) De lezer weet natuurlijk dat niets minder waar is, omdat Saskia en Rex letterlijker in de aardbodem zitten dan iemand buiten Lemorne zou kunnen vermoeden. De uitdrukking 'van de aardbodem verdwenen' kan intussen ook gelezen worden in de context van de droom over het gouden ei: het ei heeft zich in de werkelijkheid geopenbaard als een houten doodskist en de twee geliefden zweven nu door het heelal - ver van de aardbodem. De nachtmerrie over het gouden ei strekt zo haar tentakels uit naar de eerste én laatste zin van de novelle. Zo bekeken zou je kunnen zeggen dat het vertelde letterlijk omsloten wordt door de droom, dat de tekst zelf in een droomwereld ingeklemd zit.

Het isolement waar de droom voor staat, wordt ook op andere momenten via het ruimtevaartmotief verbeeld. Als Rex zich realiseert dat hij Saskia definitief niet zal terugvinden, voelt hij zich 'eenzaam als een achtergelaten ruimtewandelaar'. (20) Het grasveld bij het tankstation wordt omschreven als 'een melkweg' (10) van proppen en sigarettendoosjes - een beschrijving die aan het slot van de novelle terugkomt (79). Als ruimtevaarder heeft Rex pas de controle als hij op vakantie met Lieneke avond na avond een computerspel speelt met het Italiaanse jongetje Vicenze: 'dan stond hij volledig geabsorbeerd kogels af te vuren op de

\footnotetext{
${ }^{2}$ In het vervolg van dit artikel worden van deze bron nog slechts de paginanummers genoemd.
} 
heelalmonsters die met borrelende en suizende geluiden op zijn ruimteschip afkwamen.' (28) Ook hier staat ruimtevaart garant voor bedreiging, maar in de fictieve werkelijkheid van het spel is Rex de gevaren de baas.

In de game die Rex speelt, kruist het ruimtevaartmotief het andere motief met metafictionele implicaties: het spelmotief. Dit komt niet alleen terug in het computerspel, maar ook in de badmintonwedstrijd die Rex en Lieneke spelen tegen drie Franse vakantiegangers. Daar waant Rex zich een winnaar, maar zijn latere ondergang is eveneens aan het spelmotief gekoppeld. Op weg naar zijn dood wordt Rex door Lemorne naar een parkeerstrook gebracht, 'tegenover een tennispark zonder netten'. (76) De mogelijk tot spel - wederom met een racket - is hier verdwenen; het troosteloze tennisveld markeert dat het game over is voor Rex Hofman. Betekenisvol is ook de andere droom uit Het gouden ei, die vreemd genoeg zelden in interpretaties betrokken wordt. Daarin zit Rex tegenover Saskia in een restaurant en krijgt hij 'een bord vol tennisballen opgediend. Toen hij er een opensneed kwam er een eend uit die zijn vleugels openvouwde en wegvloog.' (80) Deze droom is feitelijk een omkering van de gouden ei-nachtmerrie. Hier is geen sprake van opsluiting, maar van bevrijding - in zekere zin óók uit een gouden ei, omdat de (gele!) tennisbal een vogel herbergt. De vernietiging van de tennisballen onderstreept dat Rex' spel ten einde loopt, een einde dat hem verlost van de tankstationscène die hem in een ijzeren greep houdt. Ook de eend sluit bij die interpretatie aan: bij de noodlottige tankstop rijdt Rex bijna een 'klein Vietnamees-achtig meisje' aan 'dat een eend op wieltjes voorttrok.' (9) In de droom met de tennisballen maakt de eend zich symbolisch los van het touw - en tegelijkertijd wordt de situatie bij het tankstation opnieuw met een droombeeld geladen.

Het spelmotief is dus gekoppeld aan Rex' competitiezucht en ondergang, maar ook aan dromen en fictie (de ruimtemonsters in het videospel). Evenals het ruimtevaartmotief problematiseert het zo de grens tussen fictie en werkelijkheid. Het heeft intussen evengoed betrekking op de fictie waarmee Rex zelf flirt, als hij op zogenaamd onschuldige wijze probeert Saskia te overheersen. Aan het begin van Het gouden ei wordt de lezer deelgenoot van het grootste geheim dat Rex voor Saskia heeft, namelijk dat hij veinsde niet over een boek te beschikken en Saskia een passage op dicteersnelheid liet voordragen, terwijl hij in zijn opengeslagen boek meelas. Ook dat is spel, maar dan een machtsspel waarbij Rex een 'griezelige wellust' (12) voelde. Dit machtsspel staat niet los van het fictionele: omdat Rex het koppelt aan de praktijk van (voor)lezen en schrijven, heeft het ontegenzeggelijk een literaire dimensie.

Hoe belangrijk dat literaire aspect voor Rex is, blijkt aan het slot van Het gouden ei, als Rex zelf ten onder gaat in het machtsspel met Lemorne. Er daalt dan 'een rust in hem en een gevoel van volmaaktheid dat hij herkende van lang geleden, uit de tijd dat hij gedichten schreef'. (78) Kern van die poëtische, literaire ervaring is

dat de vraag naar zin of succes en zelfs naar schoonheid en zeggingskracht verdween - en dat het opwindende besef resteerde dat hij iets nadeed; dat hij eindelijk deed wat iets heel hoogs van hem wilde, en dat hij de zware verantwoordelijkheid droeg dat stap voor stap te blijven doen. (78)

De ultieme dichter volgt kortom het dictaat van het hogere, lost de romantische roeping in - en die romantische roeping resoneert blijkbaar in de dood. Als Rex gesmoord wordt onder de aarde, raakt dat in zijn beleving aan de allervolmaaktste esthetiek. Op dat punt wordt zijn werkelijkheid zoals de literatuur.

Tezamen laten deze passages zien dat de doodservaring en het isolement in Het gouden $e i$ verankerd zijn in de droom, het spel, het fictionele en het literaire. De analyse van het ruimtevaartmotief en het spelmotief kunnen daarom niet los gezien worden van de vraag hoe 
de werkelijkheid zich verhoudt tot de fictie. Je zou over Het gouden ei kunnen zeggen dat Saskia's nachtmerrie daarin werkelijkheid wordt. Nog een graad complexer: wellicht suggereert Krabbés manier van vertellen evengoed dat de werkelijkheid zelf een droom of een fictie is.

\section{Racisme en seksisme: ideologische kritiek op Het gouden ei}

In zijn bespreking van Het gouden ei wijst Dautzenberg erop dat Rex en Lemorne beide aangetrokken worden door daden van slechtheid, maar dat de eerste een geweten heeft en de tweede zijn geweten uitschakelt. Die visie op Rex Hofman verleent hem in zekere zin gratie. Op andere ideologische aspecten van de tekst gaan Dautzenberg en andere commentatoren echter niet in - en dat terwijl de focalisatie in Het gouden ei herhaaldelijk getuigt van seksistische en racistische visies.

De racistische blik komt vooral tot uiting in zeer negatief geladen culturele stereotypes in Rex' focalisatie. Hierboven kwam al het 'Vietnamees-achtig meisje' (9) aan de orde, waarbij de aanduiding 'Vietnamees-achtig' de neiging laat zien om mensen met een Aziatisch uiterlijk te classificeren op basis van hun land van herkomst. Het achtervoegsel 'achtig' suggereert dat Rex daar niet in slaagt en ook later wordt duidelijk dat hij mensen uit Zuidoost-Azië slechts in reducties kan vangen: onder de badmintonnende Fransen bevindt zich een 'Chinees of Vietnamees meisje'. (29)

Deze markeringen van etniciteit laten zien dat Rex andere personages sterk op uiterlijke basis beoordeelt, zeker omdat het voor de plot op geen enkele manier ter zake doet waar de meisjes in kwestie vandaan komen. De schets van de situatie bij het tankstation omvat zelfs een racistisch stereotype: 'Een neger in een Afrikaanse jurk keek zoekend rond terwijl hij twee ijsjes aan de punten omhoog hield.' (10) De kale Fransman bij het badmintonnen, intussen, doet Rex aan een 'mongool' denken. Als hij in zee zit, focaliseert Rex hem 'als een vadsige Birmese prins op een troon'. (30) In dat stereotype krijgt Zuidoost-Azië definitief een negatieve connotatie. Het beeld wordt later in het badmintonspel versterkt, als de kale Fransman tijdens de wedstrijd aan Rex' voeten neervalt. Daar verheft Rex Hofman zich letterlijk en figuurlijk boven de Birmese prins, de koloniale hiërarchie bevestigend.

Evengoed is het perspectief van Rex seksistisch. Saskia wordt al op de eerste pagina van de novelle opgevoerd met een 'breiwerkje' (7), een keuze waarmee Krabbé ook buiten Rex' blik om voor een stereotiep perspectief op dit vrouwelijke personage kiest. Als ze bij het tankstation verdwijnt, denkt Rex aanvankelijk dat zij 'zich uitgebreid [stond] op te tutten bij het toilet.' (14) Hij brengt haar ook in verband met een slechte smaak: 'Zou hij haar gaan wakker schudden uit de Marie Claire waar ze bij de tijdschriftrekken in stond te dromen?' (14) Later zien we stereotiepe gerichtheid op oppervlakkig, uiterlijk vertoon terug als Rex zich voorstelt hoe Saskia hem een fles exotische drank cadeau doet - 'niet te zuipen natuurlijk, maar met veel zorg uitgekozen op het mooie etiket.' (75)

Rex, zelf een dichterlijk figuur en een schrijver, zet zijn vriendin kortom weg als een inhoudsloze ijdeltuit en omdat Saskia in Het gouden ei niet focaliseert, wordt ze ook nooit meer dan dat. Als Lieneke Rex vraagt wat voor iemand Saskia eigenlijk was, is zijn antwoord wat dat betreft ontluisterend: 'Zichzelf. Niet makkelijk. Mooi en sexy, en stofzuigen vond ze leuk omdat het snoer er met zo'n leuke roets weer in schoot als je klaar was.' (45) De vrouwelijke geliefde wordt hier beschreven in termen van wispelturigheid, uiterlijk en gedrag in het huishouden. Ook in Rex' affectie voor Lieneke klinkt denigrerend seksisme: hij noemt haar voor zichzelf een 'oneindig jong en fris butlertje'. (34)

Rex' focalisatie is getekend door macht, waarbij hij als witte man boven de nietwesterse en vrouwelijke personages staat. Die dominantie wordt ook geërotiseerd, want als Rex de grenzen van het betamelijke verkent, uit zich dat in '[d]e erectie van pure opwinding, iets spannends doen.' (34) Deze erectie brengt Rex heel dicht bij Lemorne, die een stijve penis 
krijgt als hij voor het eerst de mitella omknoopt die het middelpunt vormt van zijn strategie om een vrouw te ontvoeren. (54)

Niet voor niets wil Lemorne dan ook zijn eerste misdaad uitdrukkelijk op een 'meisje' richten. (48) Hoezeer Lemorne vrouwen daarbij tot een object maakt, blijkt wel uit de talloze potentiële slachtoffers die hij niet kiest. Een prostituée is voor Lemorne geen optie, omdat die 'uit hoofde van haar functie zou instappen'. (48) Het meisje in kwestie moet echter vooral beantwoorden aan Lemornes normen voor aantrekkelijke vrouwelijkheid. Om die reden valt bijvoorbeeld een telefoniste af die daadwerkelijk in zijn auto is gestapt, om hem te helpen hout op zijn imperiaal te laden. Uit Lemornes reflecties blijkt dat vrouwen in zijn ogen vooral niet met spierkracht geassocieerd mogen worden: 'zou het ontregelende van een beroep op haar spierkracht een vrouw niet op het verkeerde been zetten? - haar afleiden van haar natuurlijke qui-vive tegenover een vreemde man?' (52) Krabbé suggereert zelfs dat Lemorne zijn eigen dochter Gabriëlle niet als een volwaardige vrouw ziet. Zij helpt haar vader kort met klussen, wat genderstereotiepe vermoedens bij hem oproept: 'Een vrouw timmerde niet - had Gabriëlle daarom willen timmeren?' (52)

Waar het op vrouwen aankomt, hebben Rex en Lemorne ook een 'keurend oog' (61) met elkaar gemeen. Lemorne brengt dit in de praktijk door een geschikt slachtoffer uit te zoeken. Ook Rex heeft zo'n selecterende blik: als de mysterieuze Sandra zich meldt, schrijft Rex haar naam op 'de vrouwenpagina' in zijn agenda. (69) Die blijkt meerdere rubrieken te hebben, waaronder 'evt. te vers.' (eventueel te versieren). Het is onduidelijk wat de andere rubrieken zijn, maar gezien de raakvlakken tussen Rex en Lemorne lijkt iets macabers niet uitgesloten.

De verteller van Het gouden ei bekrachtigt dit geheel aan machtsverhoudingen, door de vrouwelijke personages nauwelijks focalisatieruimte te geven. De tekst blijft grotendeels beperkt tot mannenfantasieën - zozeer, dat Lemornes dodelijke aanrijding en zijn impulsieve moord op twee mannelijke lifters nauwelijks ruimte krijgt. Het enige vrouwelijke personage dat focaliseert is Lieneke, in het zeer korte slothoofdstuk. Waar Saskia in alle opzichten monddood wordt gemaakt, zet Lieneke de masculiene blik enigszins onder spanning - niet zozeer omdat de lezer kort toegang heeft tot haar perspectief, maar vooral omdat ze Rex' seksisme impliciet ontmaskert. Dat gebeurt bijvoorbeeld als zij na het zwemmen in de zon ligt en Rex een waterdruppeltje op haar rug ontwaart: 'Zo'n druppel op je rug, krijg je daar nou eigenlijk een sproet van als je in de zon ligt?' (26) De oplettende lezer weet dat die opmerking gekleurd is door Rex' herinneringen aan Saskia, wier rug hij het mooiste deel van haar lichaam vond: 'weerbarstig, kwetsbaar, en vol met sproeten'. (11) Via de sproet projecteert Rex Saskia's fysieke aantrekkingskracht op het lichaam van Lieneke. Die laatste doet zijn vraag echter af als een 'idée reçue' (26). In haar ogen is Rex' denkwijze niets meer dan een cliché en daarmee bekritiseert ze impliciet zijn objectiverende blik.

Haar gebruik van de Franse term 'idée reçue' laat ook zien dat Lieneke veel méér is dan een stereotiepe Marie Claire-lezeres, zoals Rex Saskia wegzet. De hoeveelheid boeken die zij op vakantie leest, is wat dat betreft veelzeggend. Bovendien prikt Lieneke niet alleen op het strand door Rex' visies heen. Als de twee een eventueel huwelijk bespreken en het gesprek op een ongemakkelijke stilte uitdraait, zegt ze: 't $\mathrm{Is}$ wel een conversation killer, zo'n huwelijksaanzoek' (34) - een opmerking waarachter ook kritiek op de romantisering van de huwelijkse rolpatronen schuilgaat. Als de focalisatie in het slothoofdstuk eenmaal bij Lieneke komt te liggen, wordt ook zij door de verteller onmiddellijk in verband gebracht met huishoudelijke taken. Het betreft hier echter 'de maandelijkse schoonmaakbeurt van haar kamer' (85), niet bepaald een activiteit die aansluit bij het gegenderde beeld van vrouwelijke hygiëne. Afgezien van deze fricties met de seksistische blik van Rex en Lemorne ontstijgen de vrouwen in Het gouden ei intussen nooit de functie van geliefde of slachtoffer. De male gaze domineert en sleurt ook niet-westerse personages mee de aardbodem in. 


\section{Slotsom}

Wat moeten leraren en leerlingen anno 2021 nog met Het gouden ei? Uit de enquête waarvan hier verslag is gedaan, blijkt onomstotelijk dat een groot deel van de docenten Nederlands nog altijd met de tekst uit de voeten kan om leerlingen kennis te laten maken met literatuur en om inhoud te geven aan de lessen verhaalanalyse, met name in de vierde klas. De nieuwe ingangen tot Krabbés novelle die hier gepresenteerd zijn, kunnen die literatuurdidactische praktijk echter verrijken op tenminste twee punten. Ten eerste bieden ze de mogelijkheid andere literairanalytische concepten met leerlingen te verkennen dan het traditionele structuralistische begrippenapparaat dat nu het literatuuronderwijs domineert. Het gouden ei leent zich prima voor discussies over metafictie, ideologie en representatie van gender en etniciteit. Met name die laatste insteek effent de weg voor de tweede verrijking: Krabbés novelle roept als tekst uit de jaren tachtig allerlei ethische vragen op over machtsverhoudingen tussen mannen en vrouwen en westerse en niet-westerse mensen, die in de eenentwintigste eeuw steviger ter discussie staan dan ooit tevoren. Het zou een gemiste kans zijn daar niet met leerlingen over te spreken, vooral omdat we anders blijven steken in het getal acht en het daaraan verwante oneindigheidsteken. 


\section{Bibliografie}

Boogaard, E. van den, 'De literatuurtheoretische begrippen tekst en lezer in het literatuuronderwijs'. In: Levende Talen Magazine, 105 (2018) 7: 21-24.

Braet, J., 'Beter een nep-ei dan een lekke binnenband. Twee van Krabbé: een knappe thriller en een selektie wielercolumns'. In: Knack, 07-11-1984.

Dalen, A. van, 'Krabbé blijft steken in anekdotes'. In: De Waarheid, 26-11-1984.

Dautzenberg, J.A., 'Het gouden ei'. In: A.G.H. Anbeek van der Meijden, J. Goedegebuure \& M. Janssens (red.), Lexicon van literaire werken. Besprekingen van Nederlandstalige literaire werken 1900-heden, Groningen 1995: 1-11.

Dera, J., 'De lezende leraar. Literatuuronderwijs in Nederland(s) als onderzoeksobject'. In: Tijdschrift voor Nederlandse Taal- en Letterkunde (TNTL), 134 (2018) 2: 146-170.

Dera, J., De praktijk van de leeslijst. Een onderzoek naar de inhoud en waardering van literatuurlijsten voor het schoolvak Nederlands in de bovenbouw havo en vwo, Amsterdam 2019.

Dera, J., 'Het begrip "literatuur" binnen het literatuuronderwijs'. In: G. Rijlaarsdam (red.), Didactiek Nederlands - Handboek, 21-03-2020.

Dera, J. \& N. Lommerde, 'Persoonlijke voorkeuren, canonieke werken en leesadviezen. Literatuur volgens leraren Nederlands in opleiding'. In: Levende Talen Tijdschrift, 21 (2020) 1: 3-13.

Fortuin, A., 'Mat in drie zetten'. In: NRC Handelsblad, 13-03-2009.

Kapteijns, J., ‘Duo Decimo. Een idee van Tim Krabbé’. In: Vooys, 17 (1999) 2: 45-48.

Krabbé, T., Het gouden ei, Groningen 1994 [1984].

Mersbergen, S. van, 'Literatuur tanken op de péage'. In: Algemeen Dagblad, 19-07-2018.

Ross, T., 'Jury verwisselt Gouden Strop met "Het Ei van Krabbé”. In: de Volkskrant, 26-06-1995.

Schouten, R., 'Het sportieve proza van Krabbé'. In: Trouw, 30-08-1984.

Temmerman, M., 'Het gouden ei’. In: Leesideeën Off Line, 31-12-2002.

Vervoort, E., Fictie in het vmbo. Een onderzoek naar de visie op fictie van een aantal leergangen voor het schoolvak Nederlands in de onderbouw van het vmbo. Nijmegen, masterscriptie Radboud Universiteit, 2018.

Vervoort, H., 'Kort verhaal van Tim Krabbé. Het geweten uitgeschakeld'. In: NRC Handelsblad, 0607-1984.

Warren, H., 'Gruwelverhaal van Tim Krabbé'. In: Provinciaalse Zeeuwse Courant, 09-06-1984.

Witte, T., Het oog van de meester. Een onderzoek naar de literaire ontwikkeling van havo- en vwoleerlingen in de tweede fase van het voortgezet onderwijs, Delft 2008. 